\title{
Dahili Membran Reaktörde Kullanılmak Üzere Yüksek Performanslı Polivinil Alkol Membran Üretimi ve Etanol-Propiyonik Asit Esterleşme Reaksiyonunda Uygulaması
}

\author{
Filiz UĞUR NİGiZ*1
}

${ }^{1}$ Kocaeli Üniversitesi, Mühendislik Fakültesi, Kimya Mühendisliği Bölümü, 41380, Kocaeli

(Alınış / Received: 02.10.2017, Kabul / Accepted: 02.03.2018, Online Yayınlanma / Published Online: 17.04.2018)

\section{Anahtar Kelimeler}

Esterleşme,

Reaktif ayırma,

Polivinil alkol membran, Membran reaktör
Özet: Bu çalışmada, tek basamaklı reaktif ayırmanın yapıldığı bir membran reaktörde kullanılmak üzere yüksek dayanıma ve su tutma kapasitesine sahip çapraz bağlı polivinil alkol (PVA) membranı üretilmiş ve modül olarak kesikli reaktörde kullanılmıştır. Etanol ve propiyonik asit arasında Amberlit IR120 katalizörü eșliğinde gerçekleșen esterleșme reaksiyonunda membran modül eklenen kesikli reaktör ve klasik kesikli reaktörün asit dönüşüm sonuçları karşılaştırılmış, membranın klasik kesikli sistemde yaptığı dönüşüm iyileştirmesi değerlendirilmiş̦tir. Reaksiyon sıcaklığının $\left(50,60,70^{\circ} \mathrm{C}\right)$, katalizör miktarının (asit kütlesine göre $\% 1,2,3)$ ve alkol:asit reaktan besleme oranının $(M=1,2,3)$ her iki reaktördeki dönüşüme etkisi belirlenerek en iyi koşullar belirlenmiștir. Sonuç olarak membranın modül olarak eklendiği, sürekli ayırma yapmadığı ve suyu sorpladığı membran modüllü reaktörde klasik reaktöre göre \%24-48 oranlarında dönüşüm iyileștirilmesi gerçekleştirilmiş̦tir. En yüksek dönüşüm değeri ise $70^{\circ} \mathrm{C}$ sıcaklıkta ve $\mathrm{M}=3$ besleme oranında modül kullanılan reaktörde $\% 74$ olarak elde edilmiştir.

\section{High-Performance Polyvinyl Alcohol Membrane Preparation to be Used for In-Situ Membrane Reactor and Application on Esterification Reaction of Ethanol-Propionic Acid}

\section{Keywords}

Esterification,

Reactive separation,

Polyvinyl alcohol membrane,

Membrane reactor

\begin{abstract}
In this study, high performance polyvinyl alcohol (PVA) membrane was prepared to be used in a single stage membrane reactor. PVA membrane was used as a membrane modul in a classical batch reactor. The conversion results of the reactors with and without membrane modul were compared in terms of the result of the reaction occured between ethanol and propionic acid via Amberlite IR 120. The conversion improvements were evaluated as a function of temperature in the range from $50^{\circ} \mathrm{C}$ to $70^{\circ} \mathrm{C}$, catalyst concentration (\%1-3) and alcohol:acid molar ratio ( $\mathrm{M}=1$ to 3$)$. As a result of this study, conversion improvement in the range from \%24-48 were achieved by using PVA membrane. The highest conversion result of $\% 74$ was achieved at $70^{\circ} \mathrm{C}$ when the alcohol:acid ratio was three.
\end{abstract}

\section{Giriş}

Bilimsel bilgi birikiminin artması ve yeni proseslerin geliştirilmesi ile birlikte, ürün veriminin yanı sıra sürecin de ekonomik ve çevreci olması beklentisi ön plana çıkmıştır. Buna göre; daha az enerji tüketen, daha az katalizör gerektiren, daha güvenilir işletim sağlanan, süreç boyunca yan ürünleri az olan, reaksiyon sonucunda emisyonu çevreye zarar vermeyen üretim proseslerinin kullanılması gerekmektedir. Üretim sürecinin büyük bir kısmını oluşturan kimyasal işlemlerin daha "yeșil" sürdürülebilmesi için yeni ve hibrid süreçler geliştirilmektedir. Son yıllarda reaktif ayırma adı verilen sistemlerin geliştirilmesi ile daha verimli ve ekonomik üretim yapmanın mümkün olduğu görülmüştür [1-3].

Kimyasal süreçte, reaksiyon ve ürün ayırmanın eşzamanlı gerçekleştiği sistemlere reaktif ayırma sistemi adı verilmektedir. Bu sistemler; daha düşük kurulum ve işletme maliyeti, daha az enerji tüketimi, daha kısa üretim süresine sahiptir. Ayrıca bu sistemlerde ürün seçiciliklerinin, reaktan dönüşümlerinin ve ürün verimlerinin yüksek olduğu birçok bilimsel çalışmalarda kanıtlanmıştır [4-6]. 
Geleneksel sistemlere göre birçok avantajı bulunan bu sistemlerin en bilinen örnekleri; reaktif distilasyon, reaktif adsorpsiyon, reaktif ekstraksiyon ve membran reaktörlerdir [7-9].

Membran reaktörler (MR); kimya, petrokimya, biyoteknoloji ve çevre alanında kullanılan, reaksiyon ve ayırmanın eş zamanlı yürütüldüğü reaktör sistemleridir [10, 11]. Günümüzde, ayırıcı bir bariyer olarak membranın reaksiyon sistemine entegrasyonu ile birlikte daha yüksek saflıkta ürün elde edilebildiği gibi, özellikle termodinamik olarak sinırlandırılan bazı reaksiyonlarda bu sistem kullanılmasıyla \%30'un üzerinde verim ve dönüşüm artışları görülmüştür [12, 13]. Membran reaktörler; esterleşme, transesterleşme gibi sıvı fazların yanı sıra dehidrojenasyon gibi çift fazlı sistemlerde ya da metandan hidrojen eldesi gibi tamamen gaz fazı reaksiyonlarında da kullanılmaktadır [14]. Membran reaktörler, kullanılan membranın aktivitesine göre katalitik ya da inert membran reaktör olarak iki temel gruba ayrilırlar [15]. Katalitik membran reaktörlerde kullanılan membran, hem reaktan-ürün ayırıcı bariyer olarak görev yapmakta, hem de reaksiyona doğrudan katalitik etki sağlamaktadır. Bu tip reaktörlerde, katalizör membranın yapısına katılarak ya da membrandaki aktif grupların reaksiyonu katalizlemesi sağlanarak reaksiyon gerçekleştirilmektedir $[16,17]$.

İnert membran reaktörde ise membran sadece üretilen ürünlerden bir ya da birkaçını çekerek son ürünün saflığının artmasına ve tersinir reaksiyonlarda dönüşümün artmasına sebep olmaktadır. Bu sistemlerde katalizör membranın içine değil reaksiyon ortamına eklenir ve membran sadece ayırıcı olarak görev yapar [15]. Membran reaktörler içinde kullanılan inert membranlar, ayıracakları ürüne göre farklı kimyasal yapıda üretilmektedirler. Ayrlacak ürünün kimyasal yapısına bağlı olarak membranlar fonksiyonel özellikler içermektedir [11]. Membran reaktörde kullanılan membranlar, üretildiği malzemeye göre polimerik, inorganik veya karma matrisli olarak gruplandırılabilirler.

Özellikle son yıllarda pervaporatif membran reaktörlerin esterleşme reaksiyonunda kullanılması ile klasik kesikli reaktörlere göre çok yüksek dönüşüm-verim iyileştirilmesi gerçekleştirilmiştir [18-20]. Çoğunlukla hidrofilik membranların kullanıldığı ve suyun sistemden ayrılmasına yönelik tasarlanan bu sistemlerde ayırma çözünme-difüzyon modeline göre gerçekleşmekte olup, membranın alt ve üst tarafları arasında yaratılan kimyasal potansiyel gradienine bağlı olarak ayırma sağlanmaktadır [14, 21, 22]. Bu sistemde membranın üst akım bölümü çoğunlukla atmosferik basınçta tutulup, alt akım bölümünde ise vakum sağlanmaktadır.
Pervaporasyon membran reaktörde yapılan reaksiyonlardan çoğu esterleşme reaksiyonudur. Gün geçtikçe üretim hacmi artan ester sektörünün daha ekonomik ve çevreci olarak üretilmesi için pervaporasyon destekli membran reaktör kullanımı birçok avantaj sağlamaktadır. Bu nedenle literatürde asetik asit ile etanol [19], butanol [23, 24] ve propanol esterleşmesi [25], laktik asit-etanol [26] esterleşmesi gibi birçok reaksiyon pervaporasyon membran reaktörde gerçekleştirilmiştir.

Etil propiyonat da oldukça değerli bir kimyasal olup homojen ve heterojen birçok katalizörle farklı verimlerle üretilmektedir. Chandane ve arkadaşlarının 2016 yılında yaptığı çalışmada, propiyonik asit ve isopropanol arasında geçen esterleşme reaksiyonunu, polivinil alkol (PVA)polieter sülfon (PES) membranın kullanıldığ pervaporasyon destekli reaktörde ve klasik kesikli reaktörde p-Toluen sülfonik asit katalizörü eşliğinde gerçekleștirilmiştir. PV destekli sistemde kesikli reaktöre göre \%30 dönüşüm iyileşmesi elde edilmiştir [27]. Rathod ve arkadaşları da 2014 yılında PV destekli reaktörde, isopropil propiyonat üretimini gerçekleștirmişlerdir. PVA-PES membranın inert membran olarak kullanıldığı ve sülfürük asit homojen katalizörünün kullanıldığı bu hibrid sistemde, denge dönüşümü PV kullanılarak \%66'dan \%87'ye çıkarılmıştır [28]. Zhang ve arkadaşları, 2015 yılında pervaporasyon destekli ve desteksiz etanolpropiyonik asit reaksiyonunu gerçekleştirmiş, yalnızca beş saat sürdürülen deneylerde dahi dönüşümü PV kullanımıyla \%82,6'dan \%90,8'e çıkarmışlardır [29]. Chandane ve arkadaşları 2017 yılında yaptıklarında çalışmada yine PVA-PES membranı kullanarak izobutil propiyonat üretimi yapmış ve denge dönüşümünü $\mathrm{PV}$ destekli sistem kullanarak \%67'den \%88'e çıkarmayı başarmışlardır [30]. Görüldüğü gibi pervaporatif ayırmanın yapıldığı tüm membran reaktör çalışmalarında klasik kesikli reaktörlere göre çok daha yüksek asit dönüşüm değerleri elde edilmiştir.

Yapılan literatür araştırmasında, esterleşme reaksiyonun birçoğunda pervaporatif ayırma, reaktörün ardına eklenmiștir. Yani tek basamakta hem ayırma hem de reaksiyonun gerçekleștiği bir sisteme rastlanamamıștır. Bu nedenle bu çalışmada, dahili bir pervaporatif membran reaktör sisteminde kullanılmak üzere hidrofilik bir membran hazırlanarak, esterleşme reaksiyonuna katkısının belirlenmesi amaçlanmıştır. Literatürde kullanılan PVA polimerleri yüksek hidrofiliteye sahip olduğu için genellikle farklı malzemelerle harman haline getirilmiştir ancak reaktör içine adapte edilmemiştir. $\mathrm{Bu}$ çalışmada PVA membranının sulu ortamda dayanıklılığını arttırmak ve suda çözünmesini engellemek için gluteraldehit ile çapraz bağlama işlemi uygulanmıştır. Membranın çapraz bağlanma etkisini belirlemek için FTIR testi, çapraz 
bağlanmanın membran hidrofilitesine etkisini belirlemek için ise temas açısı testleri uygulanmıştır. Yapılan literatür araștırmasına göre; Amberlit 36, Amberlit 35, Amberlit 15 gibi heterojen katalizörlerle birlikle sülfürik asit gibi homojen katalizli propionik asit-alkol esterleşmesi gerçekleştirilmiştir [31-33]. $\mathrm{Bu}$ çalışmada, Amberlitin $\mathrm{H}+$ formu olan IR 120 kullanılmıştır.

$\mathrm{Bu}$ çalışmanın amacı dahili bir pervaporasyon membran reaktör sisteminde kullanılmak üzere yüksek hidrofiliteye sahip ancak asit, ester ortamına dayanıklı bir membran üretmektir. $\mathrm{Bu}$ nedenle üretilen membran, kesikli bir reaktör sistemine adapte edilmiş, membranın sorpsiyon davranışı ve dönüşüme dolaylı olarak etkisi belirlenmiştir. Membran modülü eklenmiş ve eklenmemiş kesikli reaktörlerde; katalizör oranının, sıcaklığın ve alkol:asit molar besleme oranının propiyonik asit dönüşümüne etkisi belirlenmiştir. Membranın ürünler ve reaktanlara ayrı ayrı ilgisi sorpsiyon testleri ile belirlenmiștir. Ayrica reaksiyon ortamında kullanılan membranın şişme dereceleri, desorpsiyon testi sonucu sorpladığı madde konsantrasyonu da belirlenmiștir.

\section{Materyal ve Metot}

\subsection{Materyal}

Polivinil alkol (PVA) (Mowiol- MA=125.000), hidroklorik asit (HCl) (\%37 saflıta), Amberlit IR120 (hidrojen formu) Aldrich, Türkiye firmasından, propiyonik asit (PA) (\%99 saflıkta), etil propionat (EP) (\%99 saflıta), etanol (EtOH) (\%99.9 saflıta) Merck, Türkiye firmasından, gluteraldehit (GA) (\%50 saflıkta) Alfa Aesar firmasından satın alınmıştır.

\subsection{Membran sentezi}

Polivinil alkol membranlar çözeltiden dökmebuharlaștırma tekniği ile hazırlanmıștır. Hazırlanan kütlece \%7 PVA içeren polimer-saf su çözeltisi $90^{\circ} \mathrm{C}$ sıcaklıkta, 500 rpm karıştırma hızında homojen olana kadar dört saat karıştırılmıştır. Membran çözeltisi bir gece bekletildikten sonra membran cam yüzeye dökülmüş ve oda koşullarında iki gün kurutulması sağlanmıştır. Kurutma işleminden sonra, PVA membranın sulu ortamda çözünmesini engellemek için çapraz bağlama çözeltisi hazırlanarak membranın yedi saat çapraz bağlanması sağlanmıştır. Çapraz bağlama çözeltisi kütlece $\% 2 \mathrm{GA}, \% 1 \mathrm{HCl}$, \%75 aseton ve su olacak şekilde hazırlanmıştır. Çapraz bağlanma işleminden sonra saf su ile yıkanan membranlar, $60^{\circ} \mathrm{C}$ sıcaklıkta etüvde üç saat kurutulmuştur. Bu sayede membranların içerisindeki kalan kimyasalların uçması sağlanmıştır. Kurutulduktan sonra $4 * 13 \mathrm{~cm}$ boyutlarında düzlemsel olarak elde edilen membran, dairesel bir şekilde kıvrılarak, birkaç katmanlı spiral şekil haline getirilmiş ve reaksiyon çözeltisinin içine daldırılmak için hazırlanmıştır.

\subsection{Membran karakterizasyonu}

Çapraz bağlama işleminin gerçekleștiğini belirlemek için çapraz bağlı ve bağsız PVA membranlarının FTIR analizleri yapılmıștır. Bağlı ve bağsız membranların yüzeylerinin hidrofilite değişimlerinin belirlenmesi için Attension KSV cihazı ile yüzey temas açıları ölçülmüştür. Saf PVA membranın morfolojik analizi Taramalı Elektron Mikroskobu (SEM) ile belirlenmiştir.

\subsection{Sorpsiyon ve desorpsiyon testleri}

Hazırlanan PVA membranının reaktan ve ürünlere karşı ilgisini belirlemek için sorpsiyon testleri yapılmıştır. Oda sıcaklığında ilk ağırlıkları belirlenen membranlar 120 saat süre ile su, etanol, propiyonik asit ve etil propiyonat maddelerinde bekletilmiștir. Saat başı çözgenlerden alınan membranlar tartılarak, membrana sorplanan sıvı miktarları belirlenerek Denklem 1'e göre her bir madde için şişme dereceleri belirlenmiștir.

Ş.D. (\%), şişme derecesini, $\mathrm{W}_{\text {ilk }}$ membranın sıvı içinde tutulmadan önceki ağırlığını $W_{\text {son }}$ ise sıvı sorplamış membran ağırlığını temsil etmektedir.

$$
\text { Ş. D. }(\%)=\frac{W_{\text {son }}-W_{i l k}}{W_{i l k}} * 100
$$

Esterleșme deneyi sonrasında, reaksiyon ortamına eklenen membran modülü alınarak tartılmış ve membranın reaksiyon ortamında şişme derecesi de Denklem 1 ile belirlenmiştir. Ayrıca kullanılan bu membran, 1 mbar basınçta, sabit tartıma gelene kadar desorpsiyon işlemi yapılmıştır [34]. Bu test, membranın içindeki sıvıların vakum ortamında buharlaştırılarak çekilmesine ve sıvı azot ortamında sıvılaştırılarak elde edilmesine dayanmaktadır. Membrandan alınan sıvı TCD dedektörlü Gaz Kromatografisi (GC) cihazında analiz edilmiştir.

\subsection{Esterleşme reaksiyonu}

Tersinir bir reaksiyon olan ve sonucunda ürün olarak su ve etil propiyonatın oluştuğu etanol-propiyonik asit esterleşmesi Şekil 1'de gösterilmektedir.

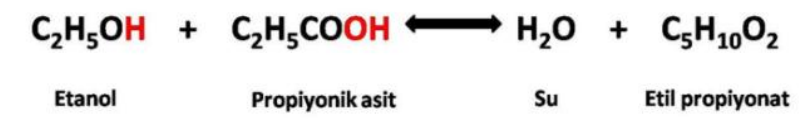

Şekil 1. Etil propiyonat kimyasal reaksiyonu

Propiyonik asit ve etanol arasındaki esterleşme reaksiyonu, membran adapte edilmiş ve edilmemiş sistemde gerçekleştirilmiştir. Membran adapte edilen sistemde, hazırlanan membranın silindir modül 
haline getirilmiş ve tamamen reaksiyon sıvısının içine daldırılmıştır. Kullanılan membran alanı yaklaşık 50 $\mathrm{cm}^{2}$ ve ağırlığı yaklaşık 2,5 gramdır. Reaktörlerin hacmi $60 \mathrm{ml}$ 'de sabit tutulmuştur. Her iki sistemde de katalizör olarak Amberlit IR120 kullanılmıştır. Deneyler yedi saat sürdürülmüştür.

Her iki sistemdeki asit dönüşümüne; sıcaklığın, katalizör miktarının, alkol/asit molar besleme oranının etkisi incelenmiştir. Şekil 2'de membran modülü adepte edilen kesikli reaktör görülmektedir.

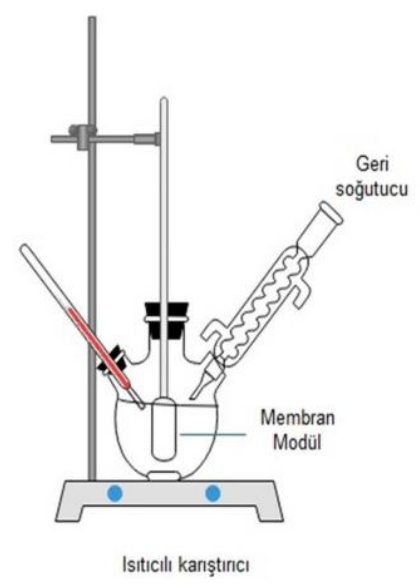

Şekil 2. Membran modülü eklenen kesikli reaktör

\subsection{Ester Analizi ve dönüşüm hesabı}

Hem membranlı hem de membransız reaktörlerin performansları asit (propiyonik) dönüşümünün bir fonksiyonu olarak belirlenmiştir. Dönüşüm eşitliği Denklem 2'de verilmektedir. Saat başı asit miktarının belirlendiği serbest asit miktarı ise Denklem 3'de verilmiştir.

$$
\begin{aligned}
& X=\frac{n_{A o}-n_{A}}{n_{A o}} * 100 \\
& \mathrm{~F}=\frac{\mathrm{N}_{\mathrm{KOH}} \mathrm{V}_{\mathrm{KOH}} \mathrm{MW}_{\mathrm{PA}}}{1000 * \mathrm{~W}}
\end{aligned}
$$

Burada $\mathrm{X}$ dönüşüm, $\mathrm{n}_{\mathrm{Ao}}$ ve $\mathrm{n}_{\mathrm{A}}$ başlangıçta ve $\mathrm{t}$ süre sonraki sınırlayıcı bileşenin mol sayıları, F kütlece serbest asit yüzdesi, $\mathrm{N}_{\mathrm{KOH}}$, kullanılan titrantın normalitesi, $\mathrm{V}_{\mathrm{KOH}}$ kullanılan titrantın hacmi, $\mathrm{MW}_{\mathrm{PA}}$ propiyonik asitin moleküler kütlesi, W titrasyonda kullanılan numune kütlesidir.

\section{Bulgular}

\subsection{Membran karakterizasyonu}

Şekil 3'de saf PVA membranın kesit görüntüsü farklı büyütme oranında görülmektedir. Görüldüğü gibi, membran kırılırken meydana gelen yönlenmenin dışında herhangi bir yapısal boşluk görülmemektedir. Membranın yoğun, homojen ve gözeneksiz olduğu SEM analizi ile kanıtlanmıştır.
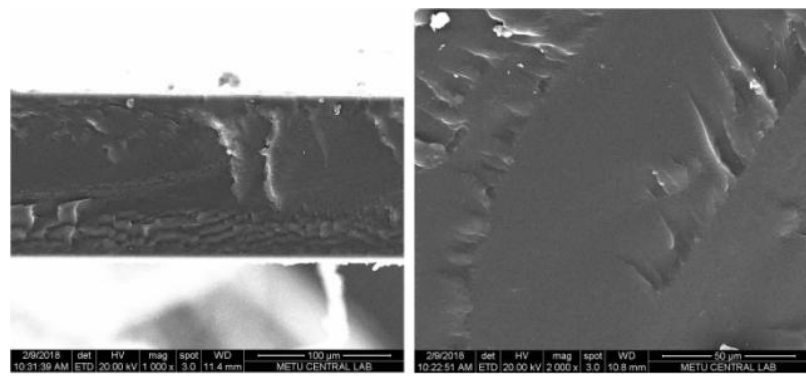

Şekil 3. Saf PVA membranın kesit SEM görüntüsü

FTIR analizi PVA içindeki bağlar ve çapraz bağlanma hakkında bilgi vermektedir. Çapraz bağlanma reaksiyonu PVA içerisindeki hidroksil $(\mathrm{OH})$ grupları ile glutaraldehit arasında gerçekleşmektedir. Dolayısıyla çapraz bağlanmayla birlikte hidroksil pik yoğunluğunun azalması beklenmektedir. Şekil 4'de saf PVA'da $3170 \mathrm{~cm}^{-1}$ bölgesinde görülen $\mathrm{OH}$ pik yoğunluğunun GA ile çapraz bağlanma reaksiyonu sonucunda $3200 \quad \mathrm{~cm}^{-1}$ bölgesinde azaldığ görülmektedir. Çapraz bağlanmanın diğer bir kanıtı ise PVA-GA reaksiyonu sonucunda oluşan asetal (C-OC) pikidir ve bu pik çapraz bağlı membranda 1130 $\mathrm{cm}^{-1}$ bölgesinde görülmektedir.

Şekil 5'de çapraz bağlanan ve bağlanmayan membran yüzeylerinin su ile yaptıkları temas açıları görülmektedir.

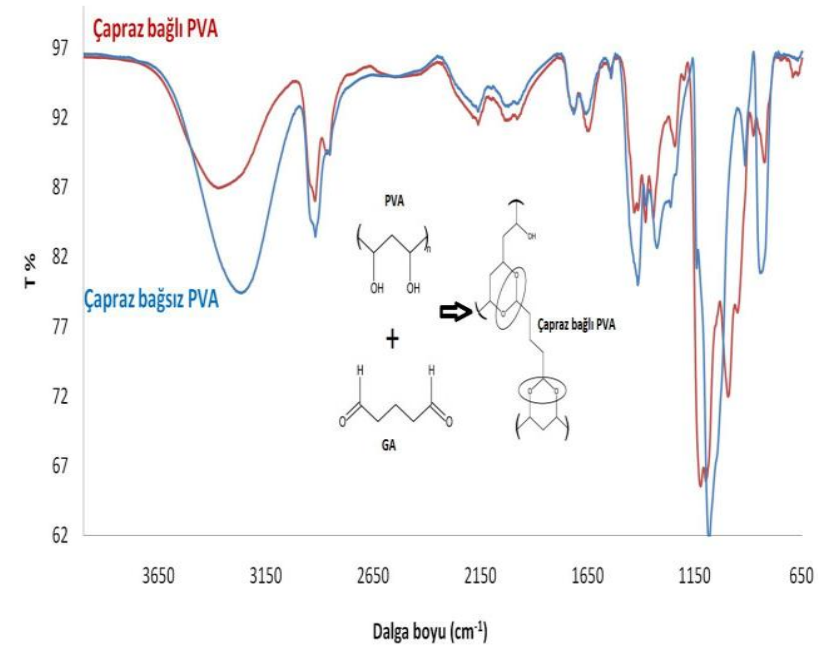

Şekil 4. Çapraz bağlı ve bağsız PVA membranın FTIR analizi
52
(a) 69

(b)
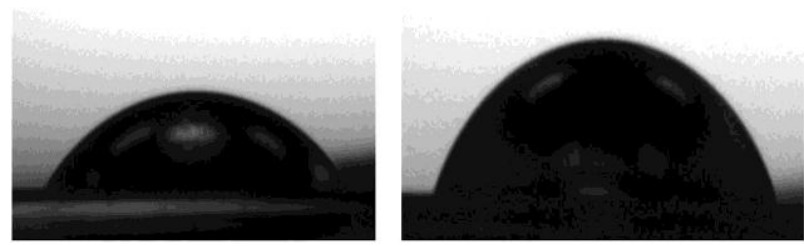

Şekil 5. Çapraz bağsız (a) ve bağlı (b) PVA membranın yüzeylerinin su ile temas açıları 
Çapraz bağlama yüksek hidrofiliteye sahip membranların, sulu ortamda çözünmelerini engellemek için yapılan bir işlemdir. Kimyasal veya isıl olarak yapılan bu işlem sonucunda membranın serbest hacimleri azalır, asidik veya sulu ortamda dayanımı artar ve şişmeye karşı gösterdiği direnç artarak reaksiyon sırasında polimerik membranın daha kararlı bir yapıda kalması sağlanır. Şekil 5a'da çapraz bağlanmayan membran yüzeyinin su tarafından daha çok ıslatıldığı ve temas açısının $52^{\circ}$ olduğu görülürken, çapraz bağlanan polimerin temas açısının $69^{\circ}$ olduğu görülmektedir.

\subsection{Sorpsiyon testi}

$\mathrm{Bu}$ çalışmada membran olarak polivinil alkol polimerinin seçilmesinin temel nedeni suya karşı gösterdiği ilgidir. PVA temelli membranın, membran reaktörde propiyonik asit-etanol esterleşme reaksiyonunda kullanıldığı durumda ise, suyu reaksiyonla eşzamanlı olarak ayırması öngörülerek çalışmalar yapılmıştır. Sabit reaksiyon koşullarında, reaksiyonla eşzamanlı olarak suyun sistemden çekilmesi ile "Le Chatelier" prensibine göre dönüşüm ve verim artmaktadır. Özellikle tersinir reaksiyonlarda, ürünlerden birinin ortamdan uzaklaşmasıyla yüksek dönüşümler elde edilmektedir. Ancak membranın seçimsiz olduğu durumlarda (genellikle filtrasyon tipi ayırım yapan gözenekli membranlarda), ürünlerin de ortamdan ayrılması hem reaksiyon dönüșümüne hem de son ürün saflığına olumsuz olarak etki edebilmektedir. Bu nedenle kullanılan membranın reaktanlara seçimli olmaması çok önemlidir.

$\mathrm{Bu}$ çalışmada kullanılan reaktanlardan biri etanol diğeri ise propiyonik asittir. Etanol hem polaritesinden dolayı hem de moleküler yapısından dolayı su ile oldukça benzer yapıdadır. Membranın, bileşen boyutuna göre ayırım yaptığı durumlarda etanol ve suyu birbirinden ayırmak çok zordur. Bu nedenle, bu çalışmada gözeneksiz ve yüksek oranda suya seçimli bir membran oluşturmak için PVA polimeri tercih edilmiştir. PVA suya seçimli olsa dahi, operasyon esnasında, polimerin yapısal hareketliliği ve serbest hacminden dolayı seçimsiz durumlar da sergileyebilmektedir. Bu nedenle, bu çalışmada çapraz bağlanarak hazırlanan PVA membranının hem reaktanlara hem de ürünlere ilgisini belirlemek amacı ile sorpsiyon testleri yapılmıştır. Yapılan testler sonucunda membranın farklı çözücülerdeki şişme dereceleri zamana bağlı olarak Şekil 6'da görülmektedir.

Şekilde görüldüğü üzere, çapraz bağlanmış membranda en yüksek şişme derecesi $\% 102$ olarak su ile elde edilirken, propiyonik asit için \%0,074 ve etanol için \%0,195 şişme değerleri elde edilmiştir. Etil propiyonat için ise membranın \%0,121 şişme derecesi sergilediği görülmüştür. Bu sonuç oldukça olumlu ve değerlidir. Çünkü membranın modül olarak eklendiği ve adsorplayıcı olarak kullanıldığı membran modüllü reaktörde, membranın tamamen suyu adsorplayacağı bu sayede görülmüştür.

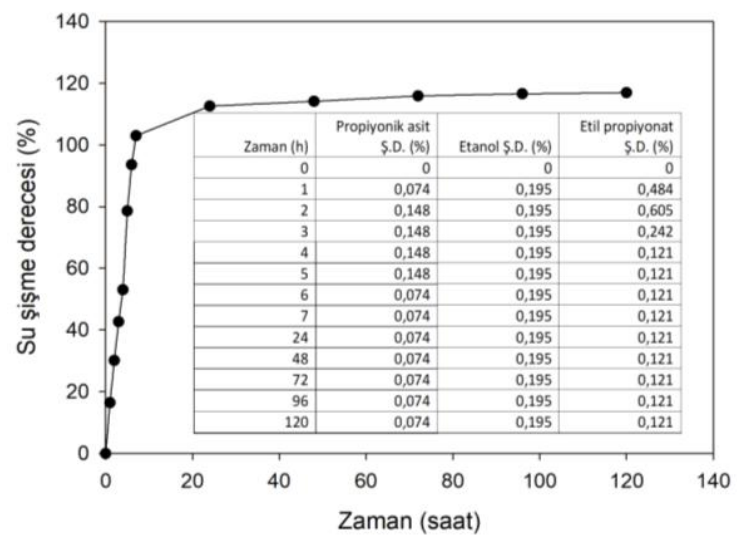

Şekil 6. Membranın çözücü içindeki şişme dereceleri

$50^{\circ} \mathrm{C}$ sıcaklıkta, $\mathrm{M}=1$ koşulunda ve katalizörün $\% 1$ olarak kullanıldığı membran modüllü reaksiyonda kullanılan membran, reaksiyon öncesi ve sonrası tartılmıștır. Bu membranın reaksiyon ortamındaki şişme derecesi belirlenmiştir. Reaksiyon öncesi 2,5 gram olarak kullanılan membran, reaksiyon sonrası 3,33 gram olarak tartılmıştır. Buna göre reaksiyon ortamındaki membranın şişme derecesi \%33,2 olarak belirlenmiștir. Saf su ortamına göre, reaksiyon ortamında membran şişme derecesinin azalması beklenen bir sonuçtur. Reaksiyon ortamında alkol, asit ve ester bulunduğundan dolayı şişme derecesi azalmıştır. Reaksiyonda kullanılan bu membran ile desorpsiyon deneyi yapılmış ve içerisindeki kimyasalların büyük bir kısmı sıvı azot ile soğutulan kapanlara alınmıştır. $\mathrm{Bu}$ karışım GC ile analiz edildiğinde, membran tarafından emilen sıvının \%99 oranında su olduğu görülmüştür. Bu sonuca göre, membran modül kullanıldığında, tüm koşullarda dönüşümün artacağı kanıtlanmıştır.

\subsection{Deney koșullarının asit dönüșümüne etkisi}

Şekil 7'de reaksiyon sıcaklığının asit dönüşümüne etkisi görülmektedir. Sicaklık $50^{\circ} \mathrm{C}^{\prime}$ den $\quad 70^{\circ} \mathrm{C}$ 'ye çlkarıldığında klasik kesikli reaktörde dönüşüm $\% 18$ 'den $\% 40,2$ 'e, membran modülününün kullanıldığ sistemde ise \%27'den \%56'ya yükselmiştir. Etanol-propiyonik asit esterleşmesi endotermik bir reaksiyondur. Dolayısıyla reaksiyon sıcaklığının artması Arrhenius eşitliğine göre hız sabitinin ve dönüşümün artmasına neden olmaktadır.

Görüldüğü gibi PVA modül eklenen reaksiyon ortamında dönüşüm iki katı kadar artış göstermiştir. Bunun nedeni, sorpsiyon ve desorpsiyon testlerinde de görüldügü gibi, kullanılan membranın büyük oranda suyu absorplaması ve reaksiyon ortamindan membrana sorplanan su dolayısıyla dönüşümün artmasıdır. Sonuç olarak, membran modül kullanılmayan reaksiyonda \%40,2 olarak elde edilen dönüşüm, modül ile birlikte \%56'ya çıkmış, yüzdesel 
olarak \%38 olarak bir artış gözlenmiştir. $70^{\circ} \mathrm{C}$ sıcaklıkta, M=1 koşulunda ve katalizörün \%1 olarak kullanıldığı membran modüllü reaksiyonda kullanılan membran, reaksiyon öncesi ve sonrası tartılmış ve reaksiyonlu ortamda membranın şişme derecesi \%59 olarak belirlenmiştir. Şişme derecesi düşük sıcaklıkta \%33,2 olarak ölçülmüştü. Şişme derecesi sıcaklıkla artmıştır. Dolayısıyla yüksek sıcaklıktaki, modül kullanılan reaktördeki dönüşüm artışı buna bağlı olarak da artmaktadır.

Şekil 8'de sabit sıcaklıkta $\left(70^{\circ} \mathrm{C}\right)$ ve sabit alkol:asit molar besleme oranında $(\mathrm{M}=1)$ katalizör miktarının asit dönüşümüne etkisi görülmektedir.

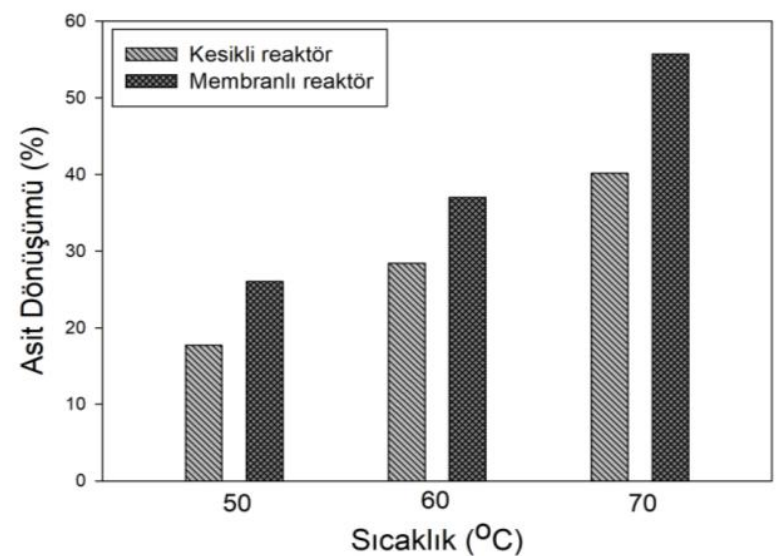

Şekil 7. Membran modüllü ve modülsüz kesikli reaktörlerde sıcaklığın dönüşüme etkisi (\%1 katalizör, $\mathrm{M}=1$ )

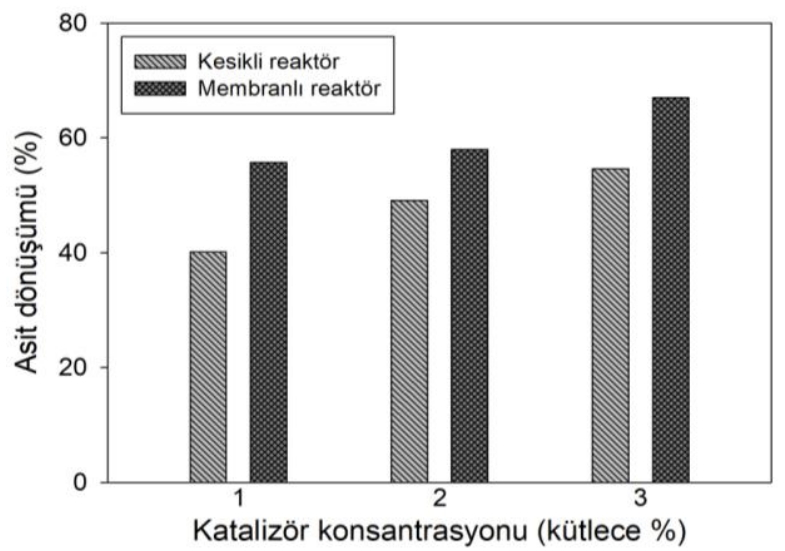

Şekil 8. Membran modüllü ve modülsüz kesikli reaktörlerde katalizör konsantrasyonunun dönüşüme etkisi $\left(70^{\circ} \mathrm{C}, \mathrm{M}=1\right)$

Katalizör konsantrasyonu, kullanılan asitin kütlece yüzdesi olarak arttırılmıştır. Beklendiği üzere katalizör miktarı arttıkça dönüşüm değerleri hem membranlı hem de membransız kesikli reaktörde artmıştır. Elde edilen dönüşümler, belirli bir süre sonunda elde edilen dönüşüm değerleri olduğu için bu artış beklenen bir sonuçtur. Membransız reaktörde katalizör oranı reaktan kütlesine göre $\% 1$ 'den \%3'e çıktığında, asit dönüşümü \%40,2'den \%54,6'ya çlkarken, membranlı sistemde \%56'dan \%68,2'ye çıkmıştır. Membran modül kullanımı ile katalizör oranının \%3 olarak kullanıldığı sistemde \%24 iyileşme elde edilmiştir. Literatürde Lilja ve arkadaşları tarafından yapılan çalıșmada, benzer koşullarda $\left(70^{\circ} \mathrm{C}\right.$ ve $\left.\mathrm{M}=1\right)$, sülfonik asit tutuklu polimerik fiber katalizörü eşliğinde propiyonik asitetanol reaksiyonu gerçekleștirilmiş, \%57 dönüşüm değeri elde edilmiştir [35]. Tiwari ve arkadaşları tarafından yapılan benzer bir çalışmada aynı koşullarda $\left(70^{\circ} \mathrm{C}\right.$ ve $\left.\mathrm{M}=1\right)$ Dowex 50Wx8-400 katalizörü kullanılarak kesikli ve pervaporasyon destekli çalışmalar yapılmıştır. Kesikli reaktörde \%53 dönüşüm elde edilirken, membran reaktörde \%65 propiyonik asit dönüşümü elde edilmiştir. Aynı araştırmacılar, reaksiyonu sülfürik asit katalizörü eşliğinde de gerçekleştirmiş, membran reaktör kullanımı ile propiyonik asit dönüşümü \%62'den \%68'e çıkarılmıştır [36]. Bu çalışmanın amacı, membran reaktörde kullanılmak üzere PVA temelli membran hazırlamak ve membranın esterleşme ortamında davranışını incelemektir. Hazırlanan bu membran, reaktörde kullanılacağı zaman sürekli ve eşzamanlı bir ayırma gerçekleşecektir. Dolayısıyla membran şişme doygunluğuna ulaşmayacağı için dönüşüm iyileştirmesinin bir miktar daha yüksek olacağı öngörülmektedir.

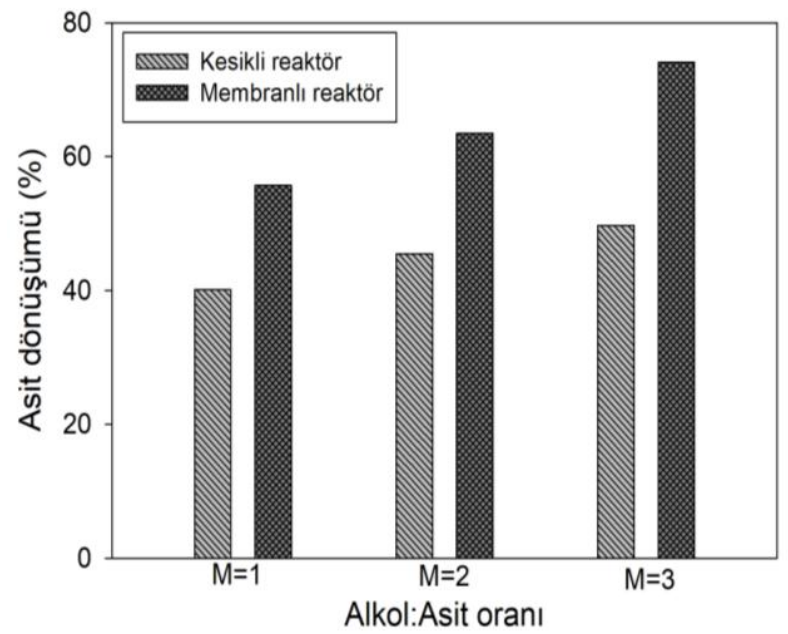

Şekil 9. Membran modüllü ve modülsüz kesikli reaktörlerde alkol:asit oranının dönüșüme etkisi $\left(70^{\circ} \mathrm{C}, \% 1\right.$ katalizör)

Şekil 9'da molar besleme oranının, sabit sıcaklık ve katalizör miktarı kullanıldığında asit dönüşümüne etkisi görülmektedir.

Sınırlayıcı bileşenin propiyonik asit olduğu bu reaksiyonda etanol oranı arttıkça substrat-substrat ve substrat-katalizör teması arttığı için dönüşüm de artmaktadır. Asit miktarına göre alkol miktarı 1'den 3'e çlktığında klasik kesikli reaktörde dönüşüm \%40,2'den \%49,7'ye çlkarken, membran modül kullanılan reaktörde \%56'dan \%74'e çıkmıştır. Belirlenen reaksiyon koşullarında $\left(70^{\circ} \mathrm{C}, \% 1\right.$ katalizör, $\mathrm{M}=3$ ), modül eklenen reaktörde, kesikli reaktördeki dönüşüme göre $\% 48$ iyileşme elde edilmiştir. 
Sabit hacimli reaktörde, alkolün molar konsantrasyonunu arttırmak için, beslenen asit miktarı azaltılmıștır. Dolayısıyla $\mathrm{M}=3$ koşullarında, sınırlayıcı bileșen asit olduğu için oluşan su miktarı, eş molar beslemeye göre oldukça azdır. $70^{\circ} \mathrm{C}$ sıcaklıkta, M=3 koşulunda ve katalizörün \%1 olarak kullanıldığı membran modüllü reaksiyonda kullanılan membran, reaksiyon öncesi ve sonrası tartılmış ve reaksiyon ortamında membranın şişme derecesi \%55 olarak belirlenmiştir. $\mathrm{M}=1$ iken $70^{\circ} \mathrm{C}$ sıcaklıkta yapılan deney sonrasında da şişme yüzdesi \%59 olarak elde edilmişti. Aynı sıcaklıkta, molar besleme oranının değişmesi, şişme yüzdesini çok fazla değiştirmemiştir. Özellikle sınırlayıcı bileşenin düşük molar miktarda kullanıldığı düşük olduğu ve reaksiyon sonucunda oluşan su miktarının az olduğu bu reaksiyon şartlarında, reaksiyon ortamında toplam su konsantrasyonu düşüktür. Membran tarafından büyük oranda adsorplanan su nedeniyle de dönüşüm değerleri artmıştır.

\section{Tartışma ve Sonuç}

$\mathrm{Bu}$ çalışmada dahili ve tek basamaklı bir membran reaktörde kullanılmak için PVA temelli yüksek su seçiciliğine ve kimyasal dayanıma sahip bir membranın üretilmesi amaçlanmıştır. Üretilen bu membranın yerleştirildiği kesikli reaktörde ve membransız kesikli reaktörde Amberlit IR120 katalizörü eşliğinde etil propiyonat üretimi gerçekleştirilmiş, membranın dönüşüme doğrudandolaylı katkısı belirlenmiştir. Bu çalışma sonucunda elde edilen temel bulgular şu şekildedir;

- Eşmolar besleme koşullarında, \%1 katalizör oranında ve $70^{\circ} \mathrm{C}$ sıcaklıkta, kesikli reaktörde $\% 40,2$ asit dönüşümü elde edilirken, PVA membranının modül olarak eklendiği reaktörde \%56 asit dönüşümü elde edilmiştir.

- Eşmolar beslemede, $70^{\circ} \mathrm{C}$ sicaklıkta, \%3 katalizör oranında kesikli reaktörde \%54,6 asit dönüşümü elde edilirken, membranlı reaktörde $\% 68,2$ dönüşüm değeri elde edilmiştir.

- $\quad 70^{\circ} \mathrm{C}$ sicaklıkta ve $\% 1$ katalizör konsantrasyonunda, alkol:asit besleme oranı 3 iken kesikli reaktörde \%49,7 dönüşüm elde edilirken, membranlı sistemde \%74 dönüşüm elde edilmiştir.

Dönüşümdeki bu artışların sebebinin sentezlenen PVA membranının ortamda oluşan suyu çekmesiyle denge reaksiyon yönünün ürünlere kayması temel nedeninin yanında, ortamdan ayrılan su nedeniyle katalizör deaktivasyonunun da azalmasıdır. Özellikle yüksek sıcaklıkta reaksiyon ortamından membran ağırlı̆̆ının \%60'ı civarında su çekilerek reaksiyon dönüşümü arttırılmıştır. Heterojen Amberlit IR120 katalizörünün kullanıldığı bu sistemde, suyun ortamdan ayrılması katalizör etkinliğini de arttırmaktadır.
Sonuç olarak, kendi ağırlığının misli kadar ortamdaki suyu çekebilen, bununla birlikte reaktanları tutmayan, dayanıklı bir PVA membranı hazırlanmıştır. Ortamdan suyu ayırdığı için dönüşüme büyük katkı sağlayan bu membranın 24 saat sürdürülen deneyler sonucunda dahi deforme olmadığl görülmüștür. Üretilen bu membranın, sürekli reaksiyon-ayırmanın gerçekleşeceği membran reaktörde kullanılması durumunda, yüksek dönüşümler elde edilmesine yardımcı olacağı öngörülmektedir.

\section{Kaynakça}

[1] Stankiewicz, A. I., Moulijn, J. A. 2000. Process Intensification: Transforming Chemical Engineering. Chemical Engineering process, January (2000), 22-34.

[2] Hessel, V. 2009. Process Windows - Gate to Maximizing Process Intensification via Flow Chemistry. Chemical Engineering and Technology, 32(2009), 1655-81.

[3] Charpentier, J. C. 2007. In the Frame of Globalization and Sustainability, Process Intensification, a Path to the Future of Chemical and Process Engineering (Molecules into Money). Chemical Engineering Journal, 134(2007), 84-92.

[4] Athankar, K. K., Wasewar, K. L., Varma, M. N., Shende, D. Z. 2016. Reactive Separation of Benzeneacetic Acid with Tri -n-caprylyl Amine: Equilibrium and Modeling. J. Chem. Eng. Data, 61(2016) 2335-2345.

[5] Kiss, A. A., Sorin, C. 2012. A review of biodiesel production by integrated reactive separation technologies. J. Chem. Technol. Biotechnol., 87(2012), 861-879.

[6] Stankiewicz, A. 2003. Reactive separations for process intensification: an industrial perspective. Chemical Engineering and Processing, 42(2003), 137-144.

[7] Buchaly, C., Kreis, P., Andrzej, G. 2007. Hybrid separation processes - Combination of reactive distillation with membrane separation. Chemical Engineering and Processing, 46(2007), 790-799.

[8] Leuch, L. M., Le Bandosz, T. J. 2007. The role of water and surface acidity on the reactive adsorption of ammonia on modified activated carbons. Carbon, 45(2007), 568-578.

[9] Wasewar, K. L. A., Heesink, B. M., Versteeg, G. F., Pangarkar, V. G. 2002. Reactive extraction of lactic acid using alamine 336 in MIBK: equilibria and kinetics. Journal of Biotechnology, 97(2002), 59-68.

[10] Basile, A. 2013. Handbook of membrane reactors 
Volume 1: Fundamental materials science, design and optimisation. Woodhead Publishing Limited, Cambridge, 696s.

[11] Basile, A., Gallucci, F. 2011. Membranes for Membrane Reactors Preparation, Optimization and Selection. John Wiley \& Sons, United Kingdom, 615s.

[12] Khajavi, S., Jansen, J. C., Kapteijn, F. 2010. Application of a Sodalite Membrane Reactor in Esterification- oupling Reaction and Separation. Catalysis Today, 156(2010), 132-39.

[13] Zhang,W., Qing, W., Chen, N., Ren, Z., Chen, J., Sun, W. 2014. Enhancement of Esterification Conversion Using Novel Composite Catalytically Active Pervaporation Membranes. Journal of Membrane Science, 451(2014), 285-92.

[14] Drioli, E., Fontananova, E. 2010. Catalytic Membranes Embedding Selective Catalysts: Preparation and Applications. ss.223-228. Barbaro P., Liguori F., ed. 2010. Heterogenized Homogeneous Catalysts for Fine Chemicals Production, Catalysis by Metal Complexes 33. Springer Science Business Media B.V., Heslington, 462s.

[15] Julbe, A., Ayral, A. 2007. Catalytic Membrane Reactors Involving Inorganic Membranes. Water Quality Control and Health, 1(2007), 30-43.

[16] Vankelecom, I. F. J. 2002. Polymeric Membranes in Catalytic Reactors. Chemical Reviews, 102(2002), 3779-3810.

[17] Dittmeyer, R., Svajda, K., Reif, M. 2004. A Review of Catalytic Membrane Layers for Gas/Liquid Reactions. Topics in Catalysis, 29(2004), 3-27.

[18] Nigiz, U. F., Hilmioglu, N. D. 2016. Simultaneous separation performance of a catalytic membrane reactor for ethyl lactate production by using boric acid coated carboxymethyl cellulose membrane. Reaction Kinetics, Mechanisms and Catalysis, 118(2016), 557-575.

[19] Hasanoğlu, A., Salt, Y., Keleşer, S., Dinçer, S. 2009. The esterification of acetic acid with ethanol in a pervaporation membrane reactor, Desalination, 245(2009), 662-669.

[20] Han, Y., Enmin, L., Lingling, M., Jie, L., Kexun, C., Jincheng, D. 2015. Coupling membrane pervaporation with a fixed-bed reactor for enhanced esterification of oleic acid with ethanol. Energy Conversion and Management, 106(2015), 1379-1386.

[21] Shao, P., Huang, R. Y. M. 2007. Polymeric Membrane Pervaporation. Journal of Membrane Science, 287(2007), 162-79.

[22] Semenova, S. I., Ohya, H., Soontarapa, K. 1997. Hydrophilic Membranes for Pervaporation: An Analytical Review. Desalination, 110(1997),
251-86.

[23] Liu, Q. L., Chen, H. F. 2002. Modeling of Esterification of Acetic Acid with N-Butanol in the Presence of $\operatorname{Zr}(\mathrm{SO} 4) 2 \bullet 4 \mathrm{H} 2 \mathrm{O}$ Coupled Pervaporation. Journal of Membrane Science, 196(2002), 171-78.

[24] Peters, T. A., Benes, N. E., Keurentjes, J. T. F. 2007. Preparation of Amberlyst-Coated Pervaporation Membranes and Their Application in the Esterification of Acetic Acid and Butanol. Applied Catalysis A: General 317(2007), 113-19.

[25] Ali, S. H. Merchant, S. Q. 2006. Kinetics of the Esterification of Acetic Acid with 2-Propanol: Impact of Different Acidic Cation Exchange Resins on Reaction Mechanism. International Journal of Chemical Kinetics, 38(2006), 593612.

[26]Pereira, C. S. M., Silva, V. M. T. M. Pinho, S. P., Rodrigues, A. E. 2010. Batch and continuous studies for ethyl lactate synthesis in a pervaporation membrane reactor. Journal of Membrane Science, 361(2010), 43-55.

[27] Chandane, V. S., Rathod, A.P., Wasewar, K.L., 2016. Enhancement of esterification conversion using pervaporation membrane reactor. Resource-Efficient Technologies, 2:S47-S52.

[28] Rathod, A. P., Wasewar, K. L., Yoo, C. K. 2014. Enhancement of Esterification of Propionic Acid with Isopropyl Alcohol by Pervaporation Reactor. Journal of Chemistry, 2014:1-4 (ID 539341).

[29] Zhang, W., Na, S., Li, W., Xing, W. 2015. Kinetic Modeling of Pervaporation Aided Esterification of Propionic Acid and Ethanol Using T - Type Zeolite Membrane. Ind. Eng. Chem. Res., 54(2015), 4940-4946.

[30] Chandane, V. S., Rathod, A. P., Wasewar, K. L. 2017. Chemical Engineering \& Processing: Process Intensi fi cation Coupling of in-situ pervaporation for the enhanced esteri fi cation of propionic acid with isobutyl alcohol over cenosphere based catalyst. Chemical Engineering\&Processing:Process Intensification, 119(2017), 16-24.

[31] Toukoniitty, B., Mikkola, J. P., Eranen, K., Salmi, T., Murzin, D. Y. 2005. Esterification of propionic acid under microwave irradiation over an ionexchange resin. Catalysis Today, 100(2005), 431-435.

[32] Lee, M., Chiu, J., Lin, H. 2002. Kinetics of Catalytic Esterification of Propionic Acid and n -Butanol over Amberlyst 35. Ind. Eng. Chem. Res., 41(2002), 2882-2887.

[33] Tsai, Y., Lin, H., Lee, M. 2011. Kinetics of Catalytic Esterification of Propionic Acid with 
Methanol over Amberlyst 36. Ind. Eng. Chem. Res., 50(2011), 1171-1176.

[34] Nigiz, F. U., Hilmioglu, N. D. 2014. Novel environmental friendly process for reducing the sulphur level in fuel: Pervaporation. International Journal of Global Warming 6(2014), 455-465.

[35] Lilja, J., Warna, J., Salmi, T., Lars J. P., Johan A., Henrik, G., Mats, R., Dmitry Yu, M. 2005.
Esterification of propanoic acid with ethanol, 1propanol and butanol over a heterogeneous fiber catalyst. Chemical Engineering Journal, 115(2005), 1-12.

[36] Tiwari, A., Amit, K., Shubhankar, B. 2017. Pervaporation study of Propionic Acid with Ethanol using heterogeneous catalyst in integrated Esterification-Pervaporation system. International Journal of ChemTech Research, 10(2017), 148-162. 